Article

\title{
The Deployment of Product-Related Environmental Legislation into Product Requirements
}

\author{
Daniela C. A. Pigosso ${ }^{1, *}$, Mariana Ferraz ${ }^{2}$, Cláudia Echevenguá Teixeira ${ }^{3}$ and \\ Henrique Rozenfeld ${ }^{2}$ \\ 1 Section of Engineering Design and Product Development, Department of Mechanical Engineering, \\ Technical University of Denmark, Produktionstorvet, Building 426, Kongens Lyngby 2800, Denmark \\ 2 Nucleous of Advanced Manufacturing, Department of Industrial Engineering, University of São Paulo, \\ Avenida Trabalhador São Carlense, 400, São Carlos SP 13566-590, Brazil; mariana.ferraz@usp.br (M.F.); \\ roz@sc.usp.br (H.R.) \\ 3 Institute for Technological Research of São Paulo, Av. Prof. Almeida Prado, 532, Cidade Universitária, \\ São Paulo SP 05508-901, Brazil; cteixeira@ipt.br \\ * Correspondence: danpi@mek.dtu.dk; Tel.: +45-2855-4942
}

Academic Editor: Giuseppe Ioppolo

Received: 21 January 2016; Accepted: 29 March 2016; Published: 6 April 2016

\begin{abstract}
Environmental legislation is increasingly changing its focus from manufacturing-oriented to product-oriented instruments. Compliance with product-related environmental legislation is achieved by the incorporation of environmental requirements into the early phases of the product development process (PDP). Nevertheless, the deployment of product-related environmental legislation into product requirements is still a challenge. This study followed an inductive approach to propose a guideline to support the identification, analysis and deployment of product requirements based on product-related environmental legislation. The guideline is composed of nine steps, clustered into three groups according to their main objective: (A) identification of environmental product-related legislation; (B) identification of legislative topics to be considered for the deployment of requirements; and $(\mathrm{C})$ creation and validation of product requirements. The product requirements deployed are to be considered during the PDP. The guideline was evaluated in an expert consultation in a large manufacturing company, suggesting that it can be used to support the systematization and deployment of product-related environmental requirements.
\end{abstract}

Keywords: legislative compliance; ecodesign; sustainability; environmental requirements; product development; innovation management

\section{Introduction}

Due to a growing concern related to resource consumption and the generation of post-consumer waste, environmental legislation is increasingly changing its focus from end-of-pipe approaches, with focus on the manufacturing processes, to a life cycle perspective [1,2] with focus on the developed products. The life cycle perspective focuses on the minimization of the environmental impacts across the entire products' life cycle, from raw material extraction and manufacturing to use and end-of-life. One of the first policies with a life cycle perspective in the European Commission was the "Integrated Product Policy" (IPP) [3], which established the ambition to improve the environmental performance of products across their life cycle, back in 2001. Some examples of other European product-related regulations include:

- "Registration, Evaluation, Authorization and Restriction of Chemicals" (REACH) [4]: aims at improving the protection of human health and the environment from the risks that can be posed by chemicals; 
- "Waste Electrical and Electronic Equipment" (WEEE) [5,6]: aims to prevent the generation of waste electrical and electronic equipment (WEEE) and increase its recyclability rates;

- "Ecodesign Directive" [7]: establishes a framework for the setting of ecodesign requirements for energy-related products;

- "Energy Labeling Directive" [8]: discusses the indication by labeling and standard product information of the consumption of energy and other resources by energy-related products;

- "Action Plan for the Circular Economy" [9]: aims at "closing the loop" of product life cycles through greater recycling and re-use, bringing benefits to both the environment and the economy.

In order to ensure legislative compliance with the product-related environmental legislation, manufacturing companies are increasingly required to integrate environmental product requirements into the early phases of the product development process (PDP), where the highest opportunities to increase the products' environmental performance are. Consequently, product-related environmental legislation became an important driver for the consideration of environmental issues during product development, i.e., for ecodesign implementation [10-14]. Ecodesign is a managerial approach that aims at improving the environmental performance of products by integrating environmental best practices into the product development and related processes (such as marketing, manufacturing, supply chain management, etc.) [15-18].

The deployment of product requirements from the environmental product-related legislation is crucial [15] to ensure that the legal issues will be properly considered during product development [19]. Currently, literature exists on the deployment and management of product requirements [20,21] based on the products' environmental performance [22] and customers' and stakeholders' needs [23-25], but limited focus has been addressed to deploying requirements from product-related legislation. Ensuring product-related environmental legal compliance is still a challenging task, especially due to the constant update and creation of new legislation [26], complex and multifaceted legal language, and the identification of relevance of legislation to the developed products and to the overlapping of requirements among different legislation in different regions (such as REACH [27] and the New Chemical Substances in China [28]).

Several research attempts have been made to understand how specific legislation can influence businesses activities in a set of sectors, such as automotive [29,30], textiles [31], cosmetics [32], naval [33], electronics [34,35], metalurgy [36], chemicals [37], pulp and paper [38], minerals [39], automotive [19], agri-food [40], industrial waste management [41], etc., has been performed in recent years. Nevertheless, there is a lack of an overall approach to guide companies across sectors to ensure compliance in a formalized and systematic way.

In a recent study, the maturity profile of a set of large manufacturing companies, from a varied set of industrial sectors, was evaluated by means of the Ecodesign Maturity Model (EcoM2) [42]. The results indicate that few companies have a formalized and monitored approach for the identification, analysis, and deployment of product-related environmental legislation into product requirements. The majority of companies still presents a non-systematic and ad hoc approach, based on subscriptions to legal databases for identification and expert consultation during the PDP. In most of the cases, legal texts are directly provided to designers and engineers, without a proper translation into product requirements.

In this context, a methodology to deploy requirements from the product-related environmental legislation is needed, enabling compliance and long-term competiveness for manufacturing companies [43]. This paper proposes a methodological process (guideline) for identifying, analyzing, and evaluating current environmental product-related legislation and for deploying product-related environmental requirements.

The intended audience is composed of ecodesign managers, EHS (Environment, Health and Safety) consultants, legislative compliance experts, and product designers and engineers. The main purpose is to provide a step-by-step approach to managing product-related environmental compliance. In addition to ensuring a more efficient and effective process in deploying product requirements, 
the guideline could also support companies to avoid business and environmental risks related to non-compliance and longer development times, directly linked to time to market.

The paper focuses exclusively on product-related environmental legislation-manufacturing and process-related legislation was not part of the scope of this paper, although some of the steps might apply in this context.

Section 2 presents the methodology employed to carry out the research. The guideline for the deployment of environmental product-related legislation into requirements is presented and discussed in Section 3. Section 4 presents the results of the evaluation of the guideline in a large manufacturing company. Conclusions and final remarks are presented in Section 5. Acknowledgments are presented after Section 5, being followed by the references.

\section{Materials and Methods}

The inductive approach [44] has been selected as the main research framework for the development of this research, and grounded theory [45] was employed as a methodology to consolidate the guideline. The inductive approach begins with detailed observations of the research context and the studied phenomenon; theories are formulated towards the end of the research based on empirical generalizations. Grounded theory is an inductive methodology that systematizes the generation of theory from systematic research that leads to the emergence of conceptual categories.

The applicability of the developed guideline was tested in an expert interview carried out in a large manufacturing company, which is in a highly regulated industry. The research was carried out in four main phases, as described in what follows. The first phase of the research aimed at identifying environmental product-related legislation databases, as well as sources of trends on the creation of new legislation. The research focused on the search for environmental product-related legislation in Brazil, the European Union (EU), and the United States of America (USA). While EU countries are often recognized as pioneers in the creation of environmental product-related legislation, the USA is increasingly launching relevant environmental product-related legislation. Brazilian legislation was also included in the scope as an example of legislative requirements in a developing country. The identification of databases was performed based on an online search using a varied set of keywords (such as "legislation database", "environmental legislation", and "product legislation") including governmental websites and websites from institutes or companies specialized in legal and/or environmental issues. The search resulted in the identification of databases for obtaining legislation related to any environmental issues, not limited to product-related legislation. Analyses of the identified databases were then performed to identify databases with information regarding product-related environmental legislation. Subsequently, specific environmental product-related legislation were identified by a search in the selected databases, so as to understand the search process that companies would go through. The identified legislation include, for example, the WEEE Directive [46]; Restriction of Use of Certain Hazardous Substances (RoHS) [47]; REACH [27]; and the Brazilian National Policy for Solid Waste [48].

The second phase of the research dealt with the development of the guideline following an inductive approach: The theory (or the guideline) was developed based on the practical deployment of requirements for two similar environmental product-related legislation (National Policy for Solid Waste [48] and European Directive 2008/98 [49]), following state-of-the-art best practices for requirement deployment. Special focus was taken on the contextual differences to be addressed for product-related environmental legislation. The analysis aimed to identify the main topics to be considered in applying the selected laws, including the goals, legal and economic principles, obligations, prohibitions, and incentives. The deployment of requirements was based on the best practices in the literature for requirement deployment and management in product development.

Based on the previous results and lessons learned during steps 1-2, a guideline that could assist companies in identifying, analyzing, and deploying product requirements from a varied set of environmental product-related legislation was developed in the third phase of the research. 
Finally, in the fourth phase of the research, an evaluation of the proposed guideline was performed based on an expert consultation in a large manufacturing multinational company following a qualitative face-to-face interview [50]. Company selection was performed based on the complexity of the legislative environment-especially in terms of product-related environmental legislation. The evaluation was supported by a semi-structured questionnaire [50], which aimed to evaluate the relevance of the proposed steps. During the study, the company representatives described with great level of detail how each step was currently being applied at the company and discussed the relevance of the proposed steps in the guideline.

The expert consultation aimed at providing a first understanding of the applicability of the guideline in an organizational context, and to identify critical attention areas to be monitored and checked during the development of detailed case studies. The next step of the research, which is beyond the scope of this article, is related to the application of the guideline in multiple case studies to identify improvement opportunities and refine the steps.

\section{Results: Guideline for the Deployment of Product Requirements from Product-Related Environmental Legislation}

The proposed guideline for the deployment of product requirements from product-related environmental legislation is divided into three groups and nine steps (Figure 1). Each group and step is further described in the subsequent sub-sessions.

A - Identification of environmental product-related legislation

-1. Selection of sources of legislation and trends

-2. Selection of relevant legislations

B - Identification of potential legal issues

-3. Analysis of the relevant legislations and topics

-4. Extraction of traceability

C - Deployment of product requirements

-5. Definition of the rationale

-6. Classification of legislation and definition of the obligatory requirements

-7. Elimination of ambiguity and clarification of unfamiliar terms

-8. Consolidation of the requirements and consistency check

-9. Comparison of the requirements

Figure 1. Guideline for the deployment of product requirements from product-related environmental legislation.

\subsection{Group A-Identification of Environmental Product-Related Legislation}

The identification of the relevant legislation is a key point for the deployment of product requirements, and can be challenging due to the large number of existing legal issues and outdated virtual databases [26]. Two steps compose this group: selection of sources of legislation and trends (Section 3.1.1); and identification of trends and legislation update (Section 3.1.2).

\subsubsection{Step 1-Selection of Sources of Legislation and Trends}

The first step aims to identify the available databases and sources of legislation. Companies should focus on legislation databases or official national webpages from the countries of interest, i.e., countries in which the company operates and commercialize their products. Databases can be easily found 
via Internet searches using common keywords, like environmental legislation or product legislation. The company should guarantee the credibility of the identified legislation databases by choosing, for example, databases from governmental agencies or institutes/companies specialized in environmental legal issues.

Examples of databases in which product-related environmental legislation can be identified in the three studied regions are: "LexML" (Brazil) [51], "National Conference of State Legislatures" (USA) [52]; and "Summaries of EU Legislation" (EU) [53]. Other specific examples include "enviroCentre.ie" (Ireland) [54], "FOEN—Federal Office for the Environment" (Switzerland) [55], and "Ministry of Agriculture, Food and Environment of Spain" (Spain) [56]. There are also some paid tools which allow for the identification of the relevant legislation, such as "EIA-TRACK" [57] (provides services to support companies to monitor current and emerging global regulations); "Compliance to Products" (C2P) [58] (guides business through updates on current legislation), and "Lema Ambiental" [59] (contains a database of Brazilian environmental legislation and provides monthly reports that indicate changes/additions/withdrawals).

Knowledge of the trends in developing or amending legislation enables the company to better adapt to the changes. Examples of databases for the identification of trends are: "ETHOS Institute" (Brazil) [60]; “European Commission" (EU) [61], "Earth Trends" (USA) [62], "Meio Ambiente Industrial” (Brazil) [63], "Buscalegis" (Brazil) [64], and "NIPR—New Ideas in Pollution Regulation" (USA) [65]. Most of the paid tools cited in the previous paragraph can also be used for the identification of trends. Participating in organizations involved in creating or updating legislation and of sector associations, which are constantly being updated with regard to the legislation related to the sector, is also recommended.

\subsubsection{Step 2-Selection of Relevant Legislation}

In order to select the relevant legislation, all environmental legislation related to the environmental performance of the company's developed products should be identified for all countries of interest. The search should be performed on the identified databases in the previous step, and a cross search should be carried out in order to include legislation that other legislation mention [17]. Subsequently, the legislation needs to be assessed in regard to its relevance, considering the characteristics of the developed products and of the company. The relevant legislation will be those that can potentially affect the development of a company's product and the products' technical characteristics (e.g., legislation dealing with the substances in the product composition, recyclability rates of the materials used in the product, energy efficiency of the product during use phase, etc.).

Relevant legislation can be identified from their descriptions, subjects, affected products, and/or sectors. The databases of legislative texts and trends are often structured in different ways and count a large variety of search engines/features. Some examples of search engine features usually presented in those databases, which can support the identification of relevant legislation and trends, include: country, industrial sector, product category, enforcement year, keywords, similar legislation, topics, and themes. The classification of the company/product according to those categories can support the identification of relevant legislation and trends.

The search for relevant legislation should be redone periodically, as well as the search for databases, due to the constant update and creation of new legislation, so as to be able to manage the evolution of legislation over time [66]. In this sense, there must be a continuous process in place for the identification of relevant legislation.

\subsection{Group B-Identification of Potential Legal Issues}

After identifying the relevant legislation (Section 3.1), it is important to identify the topics of legislation that affect each part of the organization in order to ensure legal compliance. These topics consists on all the meaningful statements of a specific legislation, as its obligations and prohibitions. 
This group is composed of two steps: analysis of the relevant legislation and topics (Section 3.2.1); and extraction of traceability (Section 3.2.2).

\subsubsection{Step 3-Analysis of the Relevant Legislation and Topics}

The analysis of the relevant legislation aims to identify all the topics in the legislation and to increase understanding about them, since the language used in legal texts is often complex [67]. The topics comprise the set of objectives of the legislation; legal and economic principles; obligations; incentives; and prohibitions. The detailed analysis of the selected legislation focus on their recommendations and selection of the legal topics (all objectives, legal and economic principles, obligations, incentives, and prohibitions of the legislation). The topics for each selected legislation should be organized, analyzed, and enumerated, allowing an easy identification and track of them.

After the analysis and enumeration of the topics of each relevant legislation, it is necessary to identify the specific topics that potentially influence the company's product development [68]. In other words, the relevant topics are those in which the legislation could affect the definition of requirements on how a particular product should be developed or managed throughout its life cycle. The promotion of recycling, as encouraged by the Brazilian National Policy for Solid Waste [48], for example, could be achieved by employing recyclable materials in the product composition. This would imply, for example, on the development of requirements related to the use of recyclable materials, which would needto be considered in the early phases of the product development process (e.g., during material selection). On the other hand, encouraging the selective collection service does not necessarily require changes on the product or its project.

After identifying the relevant topics to ensure compliance, it is necessary to conduct an assessment with respect to overlaps between the selected topics. That is because the selected topics may refer to the same subject many times. If topics are found with the same subject, one should opt for the topic with wider coverage. The topics that are relevant to the company PDP should be filtered in order to separate the topics that will be worked out for the deployment of product requirements from the rest.

\subsubsection{Step 4-Extraction of Traceability}

It is important to maintain the traceability of the selected topics of legislation in order to ensure the correct meaning of the legal text and avoid misinterpretations [66]. In this sense, it is suggested that the source and the "schema" of the identified topics are kept. The "schema" is the definition of the structure of the text in the document, containing a set of components such as the section of the chapter and paragraph [69]. The basic idea of this step is to enable product developers, engineers, and other relevant stakeholders to have access to the legal text in case there are specific questions related to the requirements formulation and/or contextual background. In other words, it means adding the reference of the legal text (section, chapter, and paragraph) to the requirement.

\subsection{Group C-Deployment of the Product Requirements}

The deployment of product requirements from legislation should be supported by a member that has knowledge of the company's portfolio of products, the products' characteristics, and the development process. This group is composed by five steps: definition of the rationale (Section 3.3.1); classification of legislation and definition of the obligatory requirements (Section 3.3.2); elimination of ambiguity and clarification of unfamiliar terms (Section 3.3.3); consolidation of the requirements and consistency check (Section 3.3.4); and comparison of the requirements (Section 3.3.5).

\subsubsection{Step 5-Definition of the Rationale}

During the requirements definition, it is important to be able to understand not only "what" should be done and "how" to do it, but also "why" this should be done [70]. In this context, it is important to develop an explanation to justify the importance of the requirement (the rationale). To define the rationale, the team in charge for the definition of requirements needs to elaborate an 
explanation on why the selected topic impacts the company's PDP and the importance or advantage, beyond legal compliance, to comply with such legislation.

For example, the topic "Take the necessary measures so that the production, collection, and transportation of hazardous waste, as well as its storage and treatment, are carried out in conditions that ensure the protection of the environment and human health, including measures to ensure traceability from production to the final destination, and control of hazardous waste" from the Directive 2008/98/EC [49] could be presented in the following rationale: "Leads to the establishment of management systems for hazardous waste management throughout the life cycle consistent with the protection of environmental and human health and to ensure the traceability throughout its life cycle".

\subsubsection{Step 6-Classification of Legislation and Definition of the Obligatory Requirements}

An important classification of the legal topics is according to its obligation once the legislation often defines not only obligations, but also initiatives that are supported by them. There are different degrees of obligation in a legal sentence [69,71], so that the requirements should be classified into required or desirable, according to the statements of the legislation. The required ones are those topics with which the company needs to comply. On the other hand, the desirable ones are those with which the company do not necessarily need to comply, but it is recommended to do so.

It is also necessary to clarify what is written in legal texts; in order to do that, it is possible to classify the topics according to the Hohfeld's taxonomy [66-68,70]. This taxonomy is based on eight elementary concepts: privilege, claim, power, immunity, "no-right", duty, liability, and disability [66,67,70]. According to the verb on a legal topic, it is possible to classify it, according to Hohfeld, so as to be able to identify whether the legal text expresses a duty or a right [67]. If the topic to be considered in a legislation has sentences with the verbs "shall, must, is required to, has to, shall not, must not, do not have right to, ... ", the requirement can be classified as duty, liability, "no-right", or disability, and the requirement will be obligatory [69]. On the other hand, for the verbs "may, has the right to, ... ", the forthcoming requirement can be classified as claim, power, immunity, or liberty [67], and the requirement will be desirable. In some cases, the legal topic has no verb. In this case, the classification followed the nomenclature of the legal text itself, classifying the topic as an objective; a principle; an obligation; an incentive; or a prohibition. The objectives, principles, obligations, and prohibitions are considered required, and the incentives are considered desirable.

\subsubsection{Step 7-Elimination of Ambiguity and Clarification of Unfamiliar Terms}

Besides being generic, another feature of the language used in legislation texts is that it is often ambiguous. Legal ambiguities can be intentional or unintentional [66]. For this reason, legislation are usually accompanied by other documents that provides support on how to interpret it [66]. These documents can be used to better understand the legislation, but caution must be taken when using such materials, since they may have been created by other organizations than the government agencies that have enacted the legislation [66]. In this sense, they may not have the same position as the agencies that enacted it, or may contain misinterpretations of the original text [66].

If these documents do not help in the disambiguation of a given topic, or if there are no documents like these available, interpretations of the legislation must be established. Sometimes it will be necessary to make decisions and perform interpretations of legislation for its deployment to be possible [66]. The maintenance of the traceability of the item concerned with the section where it was taken is very important [66], since it facilitates this query. The interpretations will vary according to the company, and whenever necessary, experts should be involved.

Another difficulty that can appear when dealing with legislation is that it is common to find unfamiliar terms [66]. Those responsible for drafting product requirements must know and understand the legal text [72]. To start this understanding, the formulation of a glossary of all specific definitions can be essential. In general, the glossary should contain important definitions and concepts defined by the legislation. Besides these, other definitions may be necessary for understanding the text. For each 
search term, it is important to add your definition to the glossary. At the end of the elaboration of requirements, it is important to keep the glossary prepared in the event that a review of these requirements is needed.

\subsubsection{Step 8-Consolidation of the Requirements and Consistency Check}

The legislation dictates the requirements of companies [73], but one must know how to define what is required for the company. The standard for the definition of requirements is to follow the subject-verb-object (SVO) structure in a sentence, in which the subjects come in first, verbs second, and objects third [67]. In order to consolidate the requirements, it is necessary to answer the following questions: (i) Who should do this? (ii) What should be done from this passage of legislation? and (iii) How should this be done? For example, the answers for the questions for the legal topic "Take the necessary measures so that the production, collection, and transportation of hazardous waste, as well as its storage and treatment, are carried out in conditions that ensure the protection of the environment and human health, including measures to ensure traceability from production to the final destination, and control of hazardous waste" are: (i) every company; (ii) being able to establish a management system for hazardous wastes and maintain its traceability; and (iii) with technical and economical capacity. From the answers to these questions, it is possible to build a requirement for each relevant topic that determines what should be done, by whom, and how. For the example above, the determined requirement is "Every company should establish a system for the management of hazardous waste, allowing traceability and control of them throughout their life cycle".

In Directive 2008/98 [49], for example, the topic "Waste management plan may contain a review of the usefulness and suitability of economic instruments and other tools for solving various problems related to waste, taking into account the need to maintain the smooth functioning of the internal market" has as answers to the question "Who?": "any enterprise"; for the question "What?": "to reduce the products' environmental impacts in order to get incentives"; and for the question "How": "to develop products with lower environmental impact throughout the life cycle, use cleaner technology, etc.". After determining the required action, it is possible to propose the requirement for taking into consideration the selected relevant topic of legislation. The standard for the definition of requirements is to follow the SVO phrase structure, in which subjects come first, and is followed by the verb and objects [67].

After defining the requirements, it is important to perform an analysis of the requirements, examining them with respect to consistency (the requirement must be easily verifiable), structure (to check if the requirement follows the SVO structure), completeness (to ensure that there is no important information missing), verifiability (the requirement must be easily verifiable), clarity (to ensure that the text is written in a simple, unambiguous, and non-confusing way), and feasibility (the implementation of the requirement should be viable). After checking, it will be possible to classify the legal requirements into two sets: legal requirements ready to implement [74]; and legal requirements that need refinement [74]. The requirements that comply with all the items (consistency, duplicity, structure, completeness, verifiability, clarity, and feasibility) are ready to be implemented, while the requirements that violate any of the items are not ready to be implemented. The refinement can be obtained by reworking the requirement or through consultations with experts in the legal field [74].

\subsubsection{Step 9-Comparison of the Requirements}

In the end, there is the need to identify whether there are similar requirements of different legislation in order to combine them to get a compact list of requirements to be applied. This is especially relevant for product-related environmental legislation.

The first activity is to identify the requirements that are about the same subject and to analyze which of the requirements is the most comprehensive. If there is a duplication of requirements of the different legislation analyzed, the most complete one should be adopted [71]. If the duplicated 
requirements are complementary, both must be excluded, and a new requirement should be developed from both.

After defining the requirements, the product development pipeline must be analyzed in order to identify in which development projects the requirements need to be taken into account. The projects affected should be amended to ensure compliance with the elaborated requirements. Furthermore, the defined requirements must be added to the PDP procedures for the requirement definition. By satisfying the defined requirements, the company will be also complying with existing legislation. It is important to remember that the identification of upcoming legislation should be performed periodically, and the requirements must be updated accordingly. The timeframe and required resources to revise the legislation depends on a set of contextual and organizational criteria, such as geographical scope and markets, complexity of the developed products, market/legislative dynamism, and compliance load of the industrial sector. The definition of periodicity for legislation updates, therefore, must be defined on a case-by-case basis based on the evaluation of the aforementioned criteria. The identification of new legislation, deletion, and modification of old legislation imply a redefinition of requirements based on the changes.

The proposed guideline is mainly focused on the identification, analysis, and deployment of requirements from product-related environmental legislation. Compliance will only be ensured with a proper requirement management during product development. In this sense, the communication of the requirements in the organization and follow-up/monitoring of compliance with the requirements during the PDP are essential steps to be taken. It is our hypothesis that the normal procedure for requirement management is applicable for product-related environmental requirements.

\section{Discussion and Evaluation of the Proposed Guideline}

The proposed guideline, presented in Section 3, was evaluated in an expert consultation with the group of Design for Environment, responsible for environmental product-related legislative compliance, of a large manufacturing company that develops and manufactures transportation means. The company was selected based on the highly regulated environment it is inserted on.

The expert consultation aimed to evaluate whether the set of steps proposed is useful to support companies in identifying, analyzing, and deploying environmental product-related legislation into product requirements, and to understand to what extent the proposed steps are currently being applied by the company.

The evaluation meeting comprised the presentation of the proposed guideline, the evaluation in light of their relevance and clearness, the analysis of which activities of the company are similar to the steps, the identification of the reasons why some steps are not applied, and the analysis of the feasibility of these steps. The results of the evaluation by the expert consultation are presented in Table 1.

The group of Design for the Environment of the company considered that the guideline can potentially support the identification, analysis, and deployment of environmental legislation on product requirements for companies aiming to comply with product-related environmental legislation. The proposed guideline was considered suitable to the industrial segment analyzed, which is highly regulated.

The group considered that the guideline is, in general, simple to understand. Furthermore, the group believes that, as the guideline consists of a systematic process, its application would permit the achievement of the same results that they currently achieve in the development of product requirements in a shorter period of time. Furthermore, the evaluation also indicated that another advantage of a systematized process is the lowest probability of some details of the legislation to not be considered in the deployment of requirements. 
Table 1. Evaluation from the expert consultation.

\begin{tabular}{|c|c|c|}
\hline & Step & Evaluation \\
\hline \multirow[t]{3}{*}{ Group A } & 1 & $\begin{array}{l}\text { Despite considering this as an interesting step, currently, there is not a systematic } \\
\text { procedure to search for environmental product-related legislation databases at the } \\
\text { company. Consequently, there is not always a critical analysis regarding the databases } \\
\text { that are being used, i.e., there is not an evaluation to check whether the database is the } \\
\text { most appropriate for the company. Currently, there is not a person responsible for the } \\
\text { identification of trends in the company. The databases currently used to obtain the } \\
\text { environmental product-related legislation provide notifications about the creation or } \\
\text { amendment of legislation, so it also acts as a database for obtaining trends. The } \\
\text { company also adopts trends through communication with other companies in the same } \\
\text { sector and accompanying political discussions of the legislation already known by the } \\
\text { company. Nevertheless, this was considered an important step, because the prediction of } \\
\text { legal setting is necessary for the company which have long development cycles. }\end{array}$ \\
\hline & 2 & $\begin{array}{l}\text { There is not a process for the identification of the relevant legislation in the company, but } \\
\text { this step was considered a valid and interesting practice to be applied. The company } \\
\text { learns about the relevant legislation through the media, in the news, or by being } \\
\text { informed by suppliers. }\end{array}$ \\
\hline & 3 & $\begin{array}{l}\text { This step is not performed in a systematic way, but each area of the company is } \\
\text { responsible for monitoring and analyzing the implications of the relevant legislation. } \\
\text { The identification of the main legal topics to be considered is not carried out } \\
\text { systematically. The group believes that this step would enable that some details of the } \\
\text { legislation are not taken into account in the deployment of requirements. }\end{array}$ \\
\hline \multirow[t]{3}{*}{ Group B } & 4 & $\begin{array}{l}\text { The group considered this step trivial and claimed to hold this activity. Due to the } \\
\text { complex legislative environment that the company is inserted on, the extraction of } \\
\text { traceability is normally carried out in their traditional requirement management system. }\end{array}$ \\
\hline & 5 & $\begin{array}{l}\text { The company already has a structured approach for the establishment of product } \\
\text { requirements based on product certifications and executes this practice for certifications. } \\
\text { The group considers the definition of the rationale for legislation to be different, since } \\
\text { the certifications define exactly what should be done while the legislation does not. }\end{array}$ \\
\hline & 6 & $\begin{array}{l}\text { This step is not applied in the company and was considered the most interesting by the } \\
\text { group. It was considered that the Hohfeld classification could be another tool in the } \\
\text { interpretation of legislation. In addition, the definition of the obligation was considered } \\
\text { an interesting distinction to be applied to the requirements. }\end{array}$ \\
\hline \multirow[t]{3}{*}{ Group C } & 7 & $\begin{array}{l}\text { The company already makes use of auxiliary legal text materials to eliminate ambiguity, } \\
\text { as proposed by this step. With respect to the unknown terms, the step was considered } \\
\text { trivial. The company is inserted in a very specialized sector, and there are several } \\
\text { internal and external stakeholders involved in getting updated knowledge related to } \\
\text { new trends and concepts. }\end{array}$ \\
\hline & 8 & $\begin{array}{l}\text { The proposition of requirements in the company is performed intuitively, and the group } \\
\text { considered this step to provide a useful way to standardize the content that is extracted } \\
\text { for each requirement, since it ensures that for every requirement the same questions will } \\
\text { be developed. This consistency check was considered similar to a process already } \\
\text { performed in the company, which is called "requirement adherence process." Since this } \\
\text { process is not carried out by the group, it was not possible to evaluate the usefulness of } \\
\text { this step. }\end{array}$ \\
\hline & 9 & $\begin{array}{l}\text { This step was also considered interesting by the group, as the company works with } \\
\text { legislation of several countries. In practice, they make this comparison intuitively, since } \\
\text { they follow European legislation, which, in general, is more restrictive than the Brazilian } \\
\text { legislation for their case. }\end{array}$ \\
\hline
\end{tabular}

Taking into account the outcome of the expert consultation, it can be concluded that, with respect to its structure, the steps of the guideline fulfill the aims of this study, although there may still be refining needed with respect to the description of each of these steps in order to make them clearer and easier to understand. Furthermore, future research is necessary to test the applicability of the guide 
in multiple cases studies for theory testing, so as to enable the identification of robust improvement opportunities based on in-depth application of the steps in the case companies.

\section{Final Remarks}

In this paper, a guideline to support companies in the identification, analysis, and deployment of product requirements from environmental product-related legislation was proposed and evaluated by an expert group in a manufacturing company. The knowledge about existing legislation is important for businesses, as it allows the maintenance of legal compliance and competitive advantage. Similarly, the knowledge of trends in regard to future legislation is important to allow businesses to be better prepared for legislative updates.

The proposed guideline presents a step-by-step approach to deploy product requirements for compliance, based on environmental product-related legislation. By providing a detailed step-by-step approach for identifying, analyzing, and deploying product-related environmental requirements, the guideline complements standards like the ISO 14006 [75], which provides overall guidance on how to manage ecodesign implementation in companies and highlights the importance of the identification of legal requirements, and Product-Oriented Environmental Management Systems (POEMS) [76]. Furthermore, the application of the defined legal requirements can be supported by the use of traditional ecodesign tools, such as the Ecodesign PILOT [77], which supports the development of products with enhanced environmental performance across their life cycle by providing a wide range of ecodesign strategies.

The more legislation used, the more complex the process is, since there is a greater amount of relevant topics to be analyzed and greater quantity of product requirements to be compared at the end of the requirement deployment. The research and conducted expert consultation indicate that the potential benefits of the application of the proposed guideline are related to the: (a) establishment of a systematic process for legislative monitoring, analysis, and deployment; (b) establishment of a more effective and efficient approach towards legislative compliance; and (c) minimization of risks related to non-compliance. The three aforementioned areas represent the main contribution of this research.

Nevertheless, further research is required to validate the developed guideline. These future studies should apply the proposed guideline in case studies in other industrial sectors, as well as involve the completion of the guideline applications in companies in order to evaluate them in practice. One of the hypotheses to be tested is whether the guidelines could also be extrapolated to non-environmental aspects. This is planned to be tested in an upcoming case study.

It is expected that the results of this project can support companies to ensure the implementation of product-related environmental legislation during the PDP, and support academia to have a more systematic approach in analyzing how a given legislation will influence the development of products with increased environmental performance.

Acknowledgments: We extend our sincere thanks to FIPT (Institution of the Technological Research Institute of Sao Paulo) for supporting this research project, for the University of São Paulo, and for the Technical University of Denmark.

Author Contributions: This research was iteratively designed by the four authors of the paper in close collaboration. The data collection and analysis was mainly carried out by Mariana Ferraz. The proposed guideline was developed by Mariana Ferraz in close collaboration with Daniela C. A. Pigosso. The paper was written and revised by Daniela C. A. Pigosso, with intense contributions from Mariana Ferraz, Henrique Rozenfeld, and Claudia Echevenguá Teixeira. Henrique Rozenfeld and Claudia Echevenguá Teixeira were the main supervisors of the research. All authors read and approved the final manuscript.

Conflicts of Interest: The authors declare no conflict of interest.

\section{References}

1. Darby, L.; Obara, L. Household recycling behaviour and attitudes towards the disposal of small electrical and electronic equipment. Resour. Conserv. Recycl. 2005, 44, 17-35. [CrossRef] 
2. Ometto, A.R.; Filho, A.G.; Souza, M.P. Implementation of life cycle thinking in Brazil's Environmental Policy. Environ. Sci. Policy 2006, 9, 587-592. [CrossRef]

3. European Commission. Green Paper on Integrated Product Policy; Office for Official Publications of the European Communities: Luxembourg, Luxembourg, 2001.

4. Askham, C.; Gade, A.L.; Hanssen, O.J. Combining REACH, environmental and economic performance indicators for strategic sustainable product development. J. Clean. Prod 2012, 35, 71-78. [CrossRef]

5. Gottberg, A.; Morris, J.; Pollard, S.; Mark-herbert, C.; Cook, M. Producer responsibility, waste minimisation and the WEEE Directive: Case studies in eco-design from the European lighting sector. Environment 2006, 359, 38-56. [CrossRef] [PubMed]

6. Pérez-Belis, V.; Bovea, M.D.; Ibáñez-Forés, V. An in-depth literature review of the waste electrical and electronic equipment context: Trends and evolution. Waste Manag. Res. 2015, 33, 3-29. [CrossRef] [PubMed]

7. European Commission. Directive 2009/125/EC of the European Parliament and of the Council of 21 October 2009 Establishing a Framework for the Setting of Ecodesign Requirements for Energy-Related Products; European Commission: Brussels, Belgium, 2009.

8. European Commission. Directive 2010/30/EU of the European Parliament and of the Council of 19 May 2010 on the Indication by Labelling and Standard Product Information of the Consumption of Energy and Other Resources by Energy-Related Products; European Commission: Brussels, Belgium, 2010.

9. European Commission. Closing the Loop - An EU Action Plan for the Circular Economy; European Commission: Brussels, Belgium, 2015.

10. Yu, J.; Hills, P.; Welford, R. Eco-Design Changes: Perspectives from China. Corp. Soc. Responsib. Environ. Manag. 2007, 124, 111-124.

11. Baumann, H.; Boons, F.; Bragd, A. Mapping the green product development field: Engineering, policy and business perspectives. J. Clean. Prod. 2002, 10, 409-425. [CrossRef]

12. Nielsen, P.H.; Wenzel, H. Integration of environmental aspects in product development: A stepwise procedure based on quantitative life cycle assessment. J. Clean. Prod. 2002, 10, 247-257. [CrossRef]

13. Pigosso, D.C.A.; Rozenfeld, H.; Seliger, G. Ecodesign Maturity Model: Criteria for methods and tools classification. Adv. Sustain. Manuf. 2011. [CrossRef]

14. Johansson, G. Success factors for integration of ecodesign in product development: A review of state of the art. Environ. Manag. Health 2002, 13, 98-107. [CrossRef]

15. Nie, L.; Pecht, M.; Ciocci, R. Regulations and market trends in lead-free and halogen-free electronics. Circuit World 2007, 33, 4-9. [CrossRef]

16. Issa, I.I.; Pigosso, D.C.A.; McAloone, T.C.; Rozenfeld, H. Leading product-related environmental performance indicators: A selection guide and database. J. Clean. Prod. 2015, 108, 321-330. [CrossRef]

17. Pigosso, D.C.A.; McAloone, T.C.; Rozenfeld, H. Characterization of the state-of-the-art and identification of main trends for Ecodesign Tools and Methods: Classifying three decades of research and implementation. J. Indian Inst. Sci. 2015, 95, 405-427.

18. Bovea, M.D.; Pérez-Belis, V. A taxonomy of ecodesign tools for integrating environmental requirements into the product design process. J. Clean. Prod. 2012, 20, 61-71. [CrossRef]

19. Makri, C.; Roy, R.; Sackett, P.J. Translating Environmental Legislation into the Engineering Design Domain; SAE Technical Papers; Society of Automotive Engineers: Warrendale, PA, USA, 2004.

20. Wei, W.; Liu, A.; Lu, S.C.-Y.; Wuest, T. Product Requirement Modeling and Optimization Method Based on Product Configuration Design. Procedia CIRP 2015, 36, 1-5. [CrossRef]

21. Montelisciani, G.; Gabelloni, D.; Fantoni, G.; Calgaro, E.G.; Taviani, C. Ordering the Chaos: A Guided Translation of Needs into Product Requirements. Procedia CIRP 2014, 21, 403-408. [CrossRef]

22. Luglietti, R.; Rosa, P.; Terzi, S.; Taisch, M. Life Cycle Assessment Tool in Product Development: Environmental Requirements in Decision Making Process. Procedia CIRP 2016, 40, 202-208. [CrossRef]

23. Sakao, T. A QFD-centred design methodology for environmentally conscious product design. Int. J. Prod. Res. 2007, 45, 4143-4162. [CrossRef]

24. Bereketli, I.; Genevois, M.E. An integrated QFDE approach for identifying improvement strategies in sustainable product development. J. Clean. Prod. 2013, 54, 188-198. [CrossRef]

25. Sakao, T.; Fargnoli, M. Creating Strategy with Demand-side Approach in Early Stages of Ecodesign. Int. J. Environ. Intell. Des. Manuf. 2013, 1, 1-24.

26. C2P. Growth of Regulations. Available online: http://goo.gl/Q7OhDv (accessed on 5 March 2016). 
27. European Commission. Regulation (EC) No. 1907/2006 of the European Parliament and of the Council of 18 December 2006. Concerning the Registration, Evaluation, Authorisation and Restriction of Chemicals (REACH), Establishing a European Chemicals Agency, amending Directive 19; European Commission: Brussels, Belgium, 2006.

28. Ministry of Environmental Protection (MEP). Provisions on the Environmental Administration of New Chemical Substances in China; MEP: Beijing, China, 2010.

29. Ahmed, S.; Ahmed, S.; Shumon, M.R.H.; Falatoonitoosi, E.; Quader, M.A. A comparative decision-making model for sustainable end-of-life vehicle management alternative selection using AHP and extent analysis method on fuzzy AHP. Int. J. Sustain. Dev. World Ecol. 2015, 23, 83-97. [CrossRef]

30. Gouda, S.K.; Jonnalagedda, S.; Saranga, H. Design for the environment: Impact of regulatory policies on product development. Eur. J. Oper. Res. 2016, 248, 558-570. [CrossRef]

31. Akbar, M. Implementing environmental discipline through legislation. Pak. Text. J. 2013, 62, 41-42.

32. Veleva, V. Legal, legislative developments. Corp. Environ. Strateg. 2005, 12, 141-145.

33. Stevens, L.; Sys, C.; Vanelslander, T.; van Hassel, E. Is new emission legislation stimulating the implementation of sustainable and energy-efficient maritime technologies? Res. Transp. Bus. Manag. 2015, 17, 14-25. [CrossRef]

34. Lueckefett, H.-J.; Orlandella, F.; Holbrook, L. A global perspective on environmentally related product legislation and regulations. In Proceedings of the 1997 IEEE International Symposium on Electronics and the Environment, San Francisco, CA, USA, 5-7 May 1997.

35. Wang, Y.; Ru, Y.; Veenstra, A.; Wang, R.; Wang, Y. Recent developments in waste electrical and electronics equipment legislation in China. Int. J. Adv. Manuf. Technol. 2009, 47, 437-448. [CrossRef]

36. Priggemeyer, S. How environmental legislation affects products from copper and copper alloys. World Metall. Erzmetall 2014, 67, 82-88.

37. Laser, M. Recent safety and environmental legislation: Germany. Process Saf. Environ. Prot. 2002, 80, $222-223$. [CrossRef]

38. Korhonen, J.; Pätäri, S.; Toppinen, A.; Tuppura, A. The role of environmental regulation in the future competitiveness of the pulp and paper industry: The case of the sulfur emissions directive in Northern Europe. J. Clean. Prod. 2015, 108, 864-872. [CrossRef]

39. Sorvari, J. Developing environmental legislation to promote recycling of industrial by-products-An endless story? Waste Manag. 2008, 28, 489-501. [CrossRef] [PubMed]

40. Cappelletti, G.; Ioppolo, G.; Nicoletti, G.; Russo, C. Energy Requirement of Extra Virgin Olive Oil Production. Sustainability 2014, 6, 4966-4974. [CrossRef]

41. Fullana i Palmer, P.; Puig, R.; Bala, A.; Baquero, G.; Riba, J.; Raugei, M. From Life Cycle Assessment to Life Cycle Management: A case study on industrial waste management policy making. J. Ind. Ecol. 2011, 15, 458-475. [CrossRef]

42. Pigosso, D.C.A.; Rozenfeld, H.; McAloone, T.C. Ecodesign maturity model: A management framework to support ecodesign implementation into manufacturing companies. J. Clean. Prod. 2013, 59, 160-173. [CrossRef]

43. Wimmer, W.; Lee, K.; Quella, F.; Polak, J. ECODESIGN_The Competitive Advantage; Springer: New York, NY, USA, 2010.

44. Gill, J.; Johnson, P. Research Methods for Managers; SAGE Publications Ltd.: London, UK, 2010.

45. Charmaz, K. Constructing Grounded Theory: A Practical Guide through Qualitative Analysis; SAGE Publications Ltd.: London, UK, 2006.

46. European Commission. Directive 2012/19/EU of the European Parliament and of the Council of 4 July 2012 on Waste Electrical and Electronic Equipment (WEEE); European Commission: Brussels, Belgium, 2012.

47. European Commission. Directive 2002/95/EC of the European Parliament and of the Council of 27 January 2003 on the Restriction of the Use of Certain Hazardous Substances in Electrical and Electronic Equipment; European Commission: Brussels, Belgium, 2003.

48. Brasil. Brazilian Law No 12.305: National Policy of Solid Waste. 2010.

49. European Commission. Directive 2008/98/EC of the European Parliament and of the Council of 19 November 2008 on Waste and Repealing Certain Directives; European Commission: Brussels, Belgium, 2008.

50. Lancaster, G. Research Methods in Management: A Concise Introduction to Research in Management and Business Consultancy; Elsevier Butterworth-Heinemann: Burlington, MA, USA, 2005. 
51. LexML (Brazil). Available online: http://www.lexml.gov.br/ (accessed on 5 March 2016).

52. National Conference of State Legislatures (USA). Available online: http://www.ncsl.org/research.aspx (accessed on 5 March 2016).

53. Summaries of EU Legislation (EU). Available online: http:/ / europa.eu/legislation_summaries (accessed on 5 March 2016).

54. EnviroCentre.ie. Available online: http://www.envirocentre.ie (accessed on 5 March 2016).

55. FOEN-Federal Office for the Environment (Switzerland). Available online: http://www.bafu.admin.ch/ (accessed on 5 March 2016).

56. Ministry of Agriculture, Food and Environment of Spain. Available online: http://www.magrama.gob.es (accessed on 5 March 2016).

57. EIA-TRACK. Available online: http:/ / www.eiatrack.org (accessed on 5 March 2016).

58. Compliance to Products. Available online: http://www.complianceandrisks.com/c2p/ (accessed on 5 March 2016).

59. Lema Ambiental. Available online: http:/ /www.lemaambiental.com.br/ (accessed on 5 Mar 2016).

60. ETHOS Institute (Brazil). Available online: http://www1.ethos.org.br/ (accessed on 5 March 2016).

61. European Commission (EU). Available online: http://ec.europa.eu/environment/index_en.htm (accessed on 5 March 2016).

62. Earth Trends (USA). Available online: http:/ /earthtrends.wri.org/ (accessed on 5 March 2016).

63. Meio Ambiente Industrial. Available online: http://rmai.com.br/ (accessed on 5 March 2016).

64. Buscalegis. Available online: http://www.egov.ufsc.br/portal/buscalegis (accessed on 5 March 2016).

65. Scott Matthews, H.; Morawski, T.B.; Nagengast, A.L.; O’Reilly, G.P.; Picklesimer, D.D.; Sackett, R.A.; Wu, P.P. Planning energy-efficient and eco-sustainable telecommunications networks. Bell Labs Tech. J. 2010, 15, 215-236. [CrossRef]

66. Otto, P.N.; Anton, A.I. Addressing Legal Requirements in Requirements Engineering. In Proceedings of the 15th IEEE International Requirements Engineering Conference, Delhi, India, 15-19 October 2007; pp. 5-14.

67. Jorshari, F.Z.; Mouratidis, H.; Islam, S. Extracting Security Requirements from Relevant Laws and Regulations. In Proceedings of the 2012 Sixth International Conference on Research Challenges in Information Science (RCIS), Valencia, Spain, 16-18 May 2011.

68. Ghanavati, S.; Amyot, D.; Peyton, L. A Systematic Review of Goal-oriented Requirements Management Frameworks for Business Process Compliance. In Proceedings of the 2011 Fourth International Workshop Requirements Engineering and Law (RELAW), Trento, Italy, 30 August 2011; pp. 25-34.

69. Sapkota, K.; Aldea, A.; Younas, M.; Duce, D.A.; Banares-Alcantara, R. Extracting meaningful entities from regulatory text: Towards automating regulatory compliance. In Proceedings of the 2012 Fifth International Workshop on Requirements Engineering and Law (RELAW), Chicago, IL, USA, 25 September 2012; pp. $29-32$.

70. Siena, A.; Irst, F.B.K.; Perini, A.; Mylopoulos, J.; Susi, A. From Laws to Requirements. In Proceedings of the 2008 Requirements Engineering and Law, RELAW '08, Barcelona, Catalunya, 9 September 2008. [CrossRef]

71. Bobkowska, A.; Kowalska, M. On Efficient Collaboration between Lawyers and Software Engineers when Transforming Legal Regulations to Law-related Requirements. In Proceedings of the 2010 2nd International Conference on Information Technology (ICIT), Gdansk, Poland, 28-30 June 2010; pp. 105-109.

72. Maxwell, J.C.; Anton, A.I. Checking Existing Requirements for Compliance with Law Using a Production Rule Model. In Proceedings of the Second International Workshop on Requirements Engineering and Law (RELAW), Atlanta, GA, USA, 1 September 2009.

73. Hassan, W.; Logrippo, L. A Governance Requirements Extraction Model for Legal Compliance Validation. In Proceedings of the Second International Workshop on Requirements Engineering and Law (RELAW), Atlanta, GA, USA, 1 September 2009.

74. Massey, A.K.; Otto, P.N.; Antón, A.I. Prioritizing Legal Requirements. In Proceedings of the Second International Workshop on Requirements Engineering and Law (RELAW), Atlanta, GA, USA, 1 September 2009.

75. International Organization for Standardization. Environmental Management Systems-Guidelines for Incorporating Ecodesign; ISO 14006; International Organization for Standardization: Geneva, Switzerland, 2010. 
76. Salomone, R.; Clasadonte, M.T.; Proto, M.; Raggi, A.; Arzoumanidis, I.; Ioppolo, G.; LoGiudice, A.; Malandrino, O.; Matarazzo, A.; Petti, L.; et al. Improving Life Cycle Management (LCM) tools for the food industry: A framework of Product-Oriented Environmental Management System (POEMS). In Proceedings of the 6th SETAC World Congr, Berlin, Germany, 20-24 May 2012.

77. Wimmer, W.; Pamminger, R.; Stachura, M.; Grab, R. ECODESIGN in the electronics industry-Achieving legal compliance with the EU-directives and environmentally improving products by using the new EEE-PILOT. In Proceedings of the Eco Design 2005 Fourth International Symposium on Environmentally Conscious Design and Inverse Manufacturing, Tokyo, Japan, 12-14 December 2005; pp. 671-677.

(C) 2016 by the authors; licensee MDPI, Basel, Switzerland. This article is an open access article distributed under the terms and conditions of the Creative Commons by Attribution (CC-BY) license (http:/ / creativecommons.org/licenses/by/4.0/). 